\title{
Barium and Radium Complexation with Ethylenediaminetetraacetic Acid in Aqueous Alkaline Sodium Chloride Media
}

\author{
Artem V. Matyskin $^{1}$ (D) Niklas L. Hansson ${ }^{1}$ (D) Paul L. Brown ${ }^{2} \cdot$ \\ Christian Ekberg 1
}

Received: 23 February 2017/ Accepted: 13 July 2017/Published online: 20 October 2017

(C) The Author(s) 2017. This article is an open access publication

\begin{abstract}
The speciation of $\mathrm{Ra}^{2+}$ and $\mathrm{Ba}^{2+}$ with EDTA was investigated at $25^{\circ} \mathrm{C}$ in aqueous alkaline $\mathrm{NaCl}$ media as a function of ionic strength $\left(0.2-2.5 \mathrm{~mol} \cdot \mathrm{L}^{-1}\right)$ in two $\mathrm{pH}$ regions where the EDTA $^{4-}$ and HEDTA $^{3-}$ species dominate. The stability constants for the formation of the $[\mathrm{BaEDTA}]^{2-}$ and $[\mathrm{RaEDTA}]^{2-}$ complexes were determined using an ion exchange method. Barium-133 and radium-226 were used as radiotracers and their concentrations in the aqueous phase were measured using liquid scintillation counting and gamma spectrometry, respectively. The specific ion interaction theory (SIT) was used to

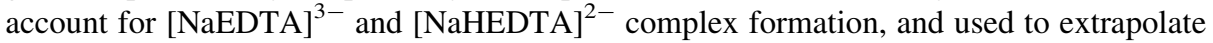
the logarithms of the apparent stability constants $\left(\log _{10} K\right)$ to zero ionic strength $\left(\right.$ BaEDTA $^{2-}: 9.86 \pm 0.09$; RaEDTA $\left.{ }^{2-}: 9.13 \pm 0.07\right)$ and obtain the $\mathrm{Ba}^{2+}$ and $\mathrm{Ra}^{2+}$ ion interaction parameters: $\quad\left[\varepsilon\left(\mathrm{Na}^{+}, \quad \mathrm{BaEDTA}^{2-}\right)=-(0.03 \pm 0.11) ; \quad \varepsilon\left(\mathrm{Na}^{+}\right.\right.$, $\left.\left.\operatorname{RaEDTA}^{2-}\right)=-(0.10 \pm 0.11)\right]$. It was found that in the $\mathrm{pH}$ region where HEDTA ${ }^{3-}$ dominates, the reaction of $\mathrm{Ba}^{2+}$ or $\mathrm{Ra}^{2+}$ with the HEDTA ${ }^{3-}$ ligand also results in the formation of the BaEDTA ${ }^{2-}$ and RaEDTA ${ }^{2-}$ complexes (as it does in the region where the EDTA $^{4-}$ ligand dominates) with the release of a proton. Comparison of the ion interaction parameters of $\mathrm{Ba}^{2+}$ and $\mathrm{Ra}^{2+}$ strongly indicates that both metal ions and their EDTA complexes have similar activity coefficients and undergo similar short-range interactions in aqueous $\mathrm{NaCl}$ media.
\end{abstract}

Keywords Alkaline-earth metal · EDTA · Complex formation · Activity coefficient $\cdot$ Specific ion interaction theory $\cdot$ Infinite dilution

Artem V. Matyskin

matyskin@chalmers.se

1 Nuclear Chemistry and Industrial Materials Recycling Groups, Energy and Materials Division, Chemistry and Chemical Engineering Department, Chalmers University of Technology,

Kemivägen 4, 41296 Gothenburg, Sweden

2 Rio Tinto Growth and Innovation, 1 Research Avenue, Bundoora 3083, VIC, Australia 


\section{Introduction}

Barium and radium are members of the alkaline-earth metal group. While barium is an abundant element in the earth's crustal rocks $\left(340 \mathrm{mg} \cdot \mathrm{kg}^{-1}\right)$, radium occurs in nature only in trace amounts $\left(0.1 \mathrm{ng} \cdot \mathrm{kg}^{-1}\right)$ [1]. Radium has no stable isotopes and the most abundant radium isotope is ${ }^{226} \mathrm{Ra}$ with a half-life of 1600 years. Radium-226 is part of the ${ }^{238} \mathrm{U}$ decay chain and decays to the short lived $\left(t_{1 / 2}=3.4 \mathrm{~d}\right) \alpha$-emitting gas ${ }^{222} \mathrm{Rn}$.

Both ${ }^{226} \mathrm{Ra}$ and ${ }^{222} \mathrm{Rn}$ are among the most radiotoxic elements present in the environment [2]. As a consequence of some anthropogenic processes, ${ }^{226} \mathrm{Ra}$ is concentrated in waste streams. For example, in uranium mining, uranium is usually leached from milled uranium ore or leached in situ using sulfuric acid. After leaching, the tailings (solid and liquid residues) are usually neutralized and disposed in surface ponds in the form of a slurry [3, 4]. Predominantly, radium is rapidly dissolved in leaching and co-precipitates in the form of $\mathrm{Ba}(\mathrm{Ra}) \mathrm{SO}_{4}$ [5]. The concentration of ${ }^{226} \mathrm{Ra}$ in such tailings is higher than in the natural uranium ore and can reach up to $43.4 \mathrm{kBq} \cdot \mathrm{kg}^{-1}\left(1186.7 \mathrm{ng} \cdot \mathrm{kg}^{-1}\right)$ [6]. The background radiation levels are also increased, mostly because of radium and its decay products, for example, from 0.1 to $0.2 \mu \mathrm{Sv} \cdot \mathrm{h}^{-1}$ in reference areas such as the tailings storage facility up to $10-20 \mu \mathrm{Sv} \cdot \mathrm{h}^{-1}$ on the top of waste dumps [6]. Radium-226 concentrations up to $200 \mathrm{~Bq} \cdot \mathrm{L}^{-1}\left(0.2 \mathrm{nmol} \cdot \mathrm{L}^{-1}\right)$ also occur in water produced from the petroleum industry, which is above limits for industrial effluents [7]. Radium-226 is usually removed by addition of sulfate salts which allow it to co-precipitate in the form of $\mathrm{Ba}(\mathrm{Ra}) \mathrm{SO}_{4}$. Therefore, co-precipitation of radium with barite $\left(\mathrm{BaSO}_{4}\right)$, mostly via an inclusion (lattice replacement) process [7], is the main mechanism controlling radium behavior in the waste streams and its migration in the environment $[5,8]$. To decontaminate uranium tailings or solid residues from, e.g., the petroleum industry, it is necessary to dissolve $\mathrm{Ba}(\mathrm{Ra}) \mathrm{SO}_{4}$.

Pure radium and barium sulfate salts and their co-precipitates are, in principle, insoluble in water and aqueous solutions of mineral acids and alkali at room temperature [9] (the recommended values for the decadic logarithm of the $\mathrm{BaSO}_{4}$ and $\mathrm{RaSO}_{4}$ solubility products at zero ionic strength and $25^{\circ} \mathrm{C}$ are -9.95 and -10.21 , respectively $\left.[10,11]\right)$. At room temperature, $\mathrm{Ba}(\mathrm{Ra}) \mathrm{SO}_{4}$ can be dissolved using chelating agents. The most commercially available chelating agent for $\mathrm{Ba}(\mathrm{Ra}) \mathrm{SO}_{4}$ dissolution is ethylenediaminetetraacetic acid (EDTA) and its derivatives. Aqueous alkaline EDTA solutions have been found to be effective in the dissolution of $\mathrm{Ba}(\mathrm{Ra}) \mathrm{SO}_{4}$ and in the extraction of ${ }^{226} \mathrm{Ra}$ from uranium tailings [12]. Approximately $80-85 \%$ of ${ }^{226} \mathrm{Ra}$ was extracted from uranium tailings using a $0.04 \mathrm{~mol} \cdot \mathrm{L}^{-1}$ aqueous alkaline EDTA solution at Elliot Lake, Ontario, Canada [13]. Moreover, alkaline EDTA solutions have been used for dissolution of irradiated ${ }^{226} \mathrm{RaSO}_{4}$ targets and the preparation of ${ }^{227} \mathrm{Ac} /{ }^{223} \mathrm{Ra}$ radiopharmaceutical generators [14]. One of the reasons for the high $\mathrm{Ba}(\mathrm{Ra}) \mathrm{SO}_{4}$ solubility in alkaline EDTA solutions is the formation of a strong complex between $\mathrm{Ba}^{2+}$ or $\mathrm{Ra}^{2+}$ and EDTA. Therefore, it is necessary to know accurately the stability constants of the BaEDTA ${ }^{2-}$ and RaEDTA ${ }^{2-}$ complexes to model the $\mathrm{Ba}(\mathrm{Ra}) \mathrm{SO}_{4}$ dissolution equilibrium in alkaline EDTA systems including decontamination using EDTA.

Experimental studies of $\mathrm{Ba}^{2+}$ and $\mathrm{Ra}^{2+}$ complex formation are also important on a fundamental level. Radium and barium have similar solution chemistry and one of the main reasons for this is the similarity of the effective ionic radii, which are equal to $1.42 \AA$ for $\mathrm{Ba}^{2+}$ and $1.48 \AA$ for $\mathrm{Ra}^{2+}$ (in 8-fold coordination) [15]. Due to the high radiotoxicity of radium and its daughters, experimental thermodynamic data for radium are limited. For example, to the best of our knowledge, the experimental determination of radium activity coefficients or ion interaction parameters have never been reported in the literature. Due to 
the lack of experimental data, extrapolation of the ion interaction parameters for radium from values of the other alkaline-earth metals using ionic radii or using interaction parameters of barium directly are the methods used to calculate radium activity coefficients $[5,16,17]$. All approaches for modelling activity coefficients are semi-empirical, with one or more fitted parameters, thus the obtained ion interaction parameters can be brought into question. Therefore, an experimental study of $\mathrm{Ba}^{2+}$ and $\mathrm{Ra}^{2+}$ complex formation using a background electrolyte would be beneficial on both applied and fundamental levels.

The objective of this work was to study the complex formation of $\mathrm{Ra}^{2+}$, as well as $\mathrm{Ba}^{2+}$, with EDTA as a function of ionic strength using $\mathrm{NaCl}$ as an ionic medium. Sodium chloride is an inert ionic electrolyte which is also omnipresent in the environment. Due to the high radiotoxicity of radium, the complex formation was studied via an ion exchange method which only requires trace amounts of radium. The specific ion interaction theory (SIT) was used to extrapolate the apparent stability constants of the studied complexes to zero ionic strength, and for determining the ion interaction parameters of the species involved in the complex formation.

\section{Experimental Section}

\subsection{Sample Preparation}

The complexation of $\mathrm{Ba}^{2+}$ and $\mathrm{Ra}^{2+}$ with EDTA was studied as a function of $\mathrm{NaCl}$ ionic strength $\left(0.22,0.5,1.0,2.0\right.$ and $\left.2.5 \mathrm{~mol} \cdot \mathrm{L}^{-1}\right)$ via an ion exchange method with batch and radiotracer techniques. The method is based on the different distribution of metal ions $\left({ }^{133} \mathrm{Ba}^{2+}\right.$ or $\left.{ }^{226} \mathrm{Ra}^{2+}\right)$ and negatively charged metal-EDTA complexes using a strong cation exchange resin. Distribution experiments were performed in polypropylene tubes with aqueous phase volumes of $10 \mathrm{~mL}$ in the case of $\mathrm{Ba}^{2+}$, and $1 \mathrm{~mL}$ in the case of $\mathrm{Ra}^{2+}$, with $0.5 \mathrm{~g}\left(\mathrm{Ba}^{2+}\right)$ and $0.05 \mathrm{~g}\left(\mathrm{Ra}^{2+}\right)$ of ion exchange resin added to each tube. The ionic strength in the aqueous phase was adjusted using concentrated $\mathrm{NaCl}$ stock solutions. Different doses of $\mathrm{Na}_{2}$ EDTA stock solution were added to each sample and its concentration was varied throughout the sample series, ranging between 0 and $6.67 \times 10^{-5}$ $\mathrm{mol} \cdot \mathrm{L}^{-1}$. The apparent EDTA dissociation constants at various $\mathrm{NaCl}$ ionic strengths were determined using the SIT methodology and the $\mathrm{H}^{+}$concentration was adjusted using potentiometric titrations to maximize the molar fractions of EDTA $^{4-}\left(-\log _{10}\right.$ $\left[\mathrm{H}^{+}\right]=12.4$; more than $\left.99 \% \mathrm{EDTA}^{4-}\right)$ or $\operatorname{HEDTA}^{3-}\left(-\log _{10}\left[\mathrm{H}^{+}\right]=7.9-8.3\right.$ depending on the ionic strength; always more than $98 \%$ HEDTA $\left.^{3-}\right)$. Samples without the ion exchange resin and EDTA were prepared to measure the total radioactivity of ${ }^{133} \mathrm{Ba}^{2+}$ or ${ }^{226} \mathrm{Ra}^{2+}$ in the samples. Preliminary kinetic studies confirmed that the metal-EDTA equilibria were achieved within $24 \mathrm{~h}$ under the experimental conditions used. The experiments were performed in duplicate where each series contained 11 samples per ionic strength. All samples were kept at $25 \pm 1{ }^{\circ} \mathrm{C}$.

\subsection{Chemicals Used}

All aqueous solutions were prepared using MQ water with $18.2 \mathrm{M} \Omega \cdot \mathrm{cm}$ resistivity at $25{ }^{\circ} \mathrm{C}$ and a total organic content of less than $5 \mathrm{mg} \cdot \mathrm{L}^{-1}$. The barium stock solution was in the form of ${ }^{133} \mathrm{Ba}$ with a specific activity of $37 \mathrm{kBq} \cdot \mu \mathrm{L}^{-1}$ in $0.1 \mathrm{~mol} \cdot \mathrm{L}^{-1} \mathrm{HCl}$ with an 
additional $10 \mu \mathrm{g} \cdot \mathrm{mL}^{-1}$ of $\mathrm{BaCl}_{2}$ carrier (Eckert and Ziegler Isotope Products radionuclide purity $>99 \%$ ). Radium carbonate was synthesized from $\mathrm{RaSO}_{4}$ powder as previously described [9]. The synthesized $\mathrm{RaCO}_{3}$ was dissolved in $0.1 \mathrm{~mol} \cdot \mathrm{L}^{-1} \mathrm{HCl}$ (Sigma-Aldrich $99.999 \%$ trace metals basis) to obtain $14 \mathrm{~mL}$ of radium stock solution with a ${ }^{226} \mathrm{Ra}$ specific activity of $(2.5 \pm 0.1) \times 10^{4} \mathrm{~Bq} \cdot \mu \mathrm{L}^{-1}$. The purity of the synthesized radium stock solution was measured previously and it was found that the mass fraction of stable barium and lead was 0.2 and 0.003 , respectively [18]. The cation exchange resin was in sodium form (Biorad AG 50W-X8 200-400 mesh molecular biology grade). EDTA stock solutions were prepared from solid $\mathrm{Na}_{2}$ EDTA $2 \mathrm{H}_{2} \mathrm{O}$ (Sigma p.a. $\geq 99.0 \%$ ). The ionic strength and $-\log _{10}$ $\left[\mathrm{H}^{+}\right]$were adjusted using a $\mathrm{NaCl}$ stock solution prepared from solid $\mathrm{NaCl}$ (Sigma-Aldrich ACS reagent p.a. $\geq 99.0 \%$ ) and standard $\mathrm{NaOH}$ and $\mathrm{HCl}$ solutions (Fixanal, SigmaAldrich).

\subsection{Apparatus}

All solid chemicals were weighed on a standard analytical balance (Sartorius Quintix125D1S) and samples were kept at a constant temperature of $25 \pm 1^{\circ} \mathrm{C}$ in a shaking water bath (Julabo SW23). Potentiometric measurements were performed using two $\mathrm{pH}$ meters coupled with combined glass electrodes $(827 \mathrm{pH}$ laboratory Metrohm coupled with Metrohm Primatrode electrode and Radiometer MeterLab PHM240 coupled with A Radiometer PHC3006-9 electrode). Both electrodes were filled with a $3 \mathrm{~mol} \cdot \mathrm{L}^{-1} \mathrm{NaCl}$ reference electrolyte and calibrated using the activity scale with standard buffer solutions (NIST and SRM traceable, Certipur, Merck), and were subsequently calibrated in the concentration scale using a potentiometric titration with negligible volume change [19]. The radioactivity of ${ }^{133} \mathrm{Ba}$ was measured using liquid scintillation counting (LSC) (Perkin Elmer Guardian 1414) and aqueous ${ }^{133} \mathrm{Ba}$ samples were subsequently mixed with an Emulsifier safe LSC cocktail. The radioactivity of ${ }^{226} \mathrm{Ra}$ was measured using two High Purity Germanium detectors (HPGe) (Canberra GEM23195 closed-end coaxial HPGe detector coupled with digital spectrum analyzer Canberra-2000/A and Ortec GEM-C5060 coaxial HPGe coupled with digital spectrum analyzer Ortec DSPEC50). Both detectors were calibrated using a mixed radionuclide reference solution (NIST traceable, Eckert and Ziegler). Nuclide halflives, gamma emission energies and photon emission probabilities were taken from the Decay Data Evaluation Project [20].

\section{The Model}

The speciation of a metal ion $\left(\mathrm{M}^{2+}\right)$ with various forms of EDTA can be described by the reaction:

$$
\mathrm{M}^{2+}+\left[\mathrm{H}_{r} \mathrm{EDTA}^{(r-4)}\right] \rightleftharpoons\left[\mathrm{MH}_{r} \mathrm{EDTA}^{(r-2)}\right]
$$

where $0 \leq r \leq 6$.

The stability constant for reaction 1 at zero ionic strength is defined as: 


$$
\begin{aligned}
K_{\mathrm{MH}_{r} \mathrm{EDTA}^{(r-2)}}^{\mathrm{o}} & =K_{\mathrm{MH}_{r} \mathrm{EDTA}^{(r-2)}} \cdot \frac{\gamma_{\mathrm{MH}_{r} \mathrm{EDTA}^{(r-2)}}}{\gamma_{\mathrm{M}^{2+}} \cdot \gamma_{\mathrm{H}_{r} \mathrm{EDTA}^{(r-4)}}} \\
& =\frac{\left[\mathrm{MH}_{r} \mathrm{EDTA}^{(r-2)}\right]}{\left[\mathrm{M}^{2+}\right] \cdot\left[\mathrm{H}_{r} \mathrm{EDTA}^{(r-4)}\right]} \cdot \frac{\gamma_{\mathrm{MH}_{r} \mathrm{EDTA}^{(r-2)}}}{\gamma_{\mathrm{M}^{2+}} \cdot \gamma_{\mathrm{H}_{r} \mathrm{EDTA}^{(r-4)}}}
\end{aligned}
$$

The SIT model developed by Brønsted [21, 22], Scatchard [23], Guggenheim and Turgeon [24] can be used to express the activity coefficients $\gamma_{i}$ of an ion $i$ at ionic strengths below about $3.5 \mathrm{~mol} \cdot \mathrm{kg}^{-1}$ :

$$
\log _{10} \gamma_{i}=-z_{i}^{2} \cdot D_{\mathrm{H}}+\sum_{j} \varepsilon\left(i, j, I_{m}\right) \cdot m_{j}
$$

where $z_{i}$ is the charge of the ion $i, \varepsilon\left(i, j, I_{m}\right)$ is the interaction parameter of ion $i$ with all oppositely charged ions $j, I_{m}$ is ionic strength in $\mathrm{mol} \cdot \mathrm{kg}^{-1}, m_{j}$ is molal concentration of ion $j$ and $D_{\mathrm{H}}$ is the Debye-Hückel term which is defined as:

$$
D_{\mathrm{H}}=\frac{A \cdot \sqrt{I_{m}}}{1+1.5 \cdot \sqrt{I_{m}}}
$$

where $A$ is a temperature dependent constant equal to 0.5090 and $0.5047 \mathrm{~kg}^{1 / 2} \cdot \mathrm{mol}^{-1 / 2}$ at $25^{\circ} \mathrm{C}$ and $20^{\circ} \mathrm{C}$, respectively, for aqueous solutions [25]. The value 1.5 is the product of $B$ (a constant dependent on temperature and the solvent relative permittivity) and $a$ (distance of closest approach or effective Debye-Hückel ionic radius). In the SIT, this product is usually taken to be 1.5 to minimize the effect of ionic strength on the ion interaction parameters. In this work, each ionic strength of $\mathrm{NaCl}$ was recalculated to the molal scale (from molar) using the relevant conversion factors [25]. Substituting the activity coefficients calculated using Eq. 3 into Eq. 2 yields:

$$
\log _{10} K_{\mathrm{MH}_{r} \mathrm{EDTA}^{(r-2)}}-\Delta z^{2} \cdot D_{\mathrm{H}}=\log _{10} K_{\mathrm{MH}_{r} \mathrm{EDTA}^{(r-2)}}^{\mathrm{o}}-\Delta \varepsilon \cdot I_{m}
$$

From Eq. 5 it can be concluded that plotting the difference between the determined decadic logarithm of the apparent stability constants and $\Delta z^{2} \cdot D_{\mathrm{H}}$ against ionic strength of the same background electrolyte will result in an intercept which is the decadic logarithm of the stability constant at zero ionic strength and a slope which is the ion interaction parameter term.

Measurement of the metal ion radioactivity in the aqueous phase allows for calculation of the distribution ratio between the solid phase and the aqueous phase according to:

$$
D=\left(\frac{A_{\text {total }}-A_{\mathrm{aq}}}{A_{\mathrm{aq}}}\right) \cdot \frac{V}{m}
$$

where $A_{\text {total }}$ is the total radioactivity of the metal ion in the sample, $A_{\mathrm{aq}}$ is the radioactivity of the metal ion in the aqueous phase after the distribution equilibrium has been reached, $V$ is the solution volume $(\mathrm{mL})$ and $m$ is the mass of the ion exchange resin $(\mathrm{g})$.

The distribution ratio can also be expressed through the apparent stability constant:

$$
D=\frac{\lambda \cdot\left[\mathrm{M}^{2+}\right]}{\left[\mathrm{M}^{2+}\right]+\sum\left(K_{\mathrm{MH}_{r} \mathrm{EDTA}^{(r-2)}} \cdot\left[\mathrm{M}^{2+}\right] \cdot\left[\mathrm{H}_{r} \mathrm{EDTA}^{(r-4)}\right]\right)}
$$

where $\lambda$ is the distribution ratio without the ligand $\left(\mathrm{mL} \cdot \mathrm{g}^{-1}\right)$ and $K$ is the apparent stability constant for the $\mathrm{MH}_{r} \mathrm{EDTA}^{(r-2)}$ complex. 
The apparent dissociation constants of the $\mathrm{H}_{\mathrm{r}} \mathrm{EDTA}^{(r-4)}$ complexes can be computed via the SIT (Eq. 3) using the EDTA dissociation constants at zero ionic strength and their ion interaction parameters given in the literature [26]. The constants calculated in this manner have been used in this work. Molar fractions of the different EDTA species can be computed as a function of hydrogen ion concentration using the calculated apparent dissociation constants of $\mathrm{H}_{r}$ EDTA $^{(r-4)}$. The concentration of $\mathrm{H}^{+}$at which the molar fractions of EDTA $^{4-}$ and HEDTA ${ }^{3-}$ are maximized were calculated for all studied ionic strengths, and $-\log _{10}\left[\mathrm{H}^{+}\right]$was adjusted according to these calculations.

The hydrolysis of $\mathrm{Ba}^{2+}$ and $\mathrm{Ra}^{2+}$ at a $-\log _{10}\left[\mathrm{H}^{+}\right]$of 12.4 (the highest $-\log _{10}\left[\mathrm{H}^{+}\right]$ used in this work) can be neglected [27] compared to the metals strong complexation with EDTA. Polynuclear complexes are also not formed when a metal ion is at radiotracer levels, therefore the $\mathrm{M}^{2+}$ concentration terms in Eq. 7 cancel. Only one form of $\mathrm{H}_{r}$ EDTA $^{(r-4)}$ is dominant under each of the two experimental conditions studied. As a result, Eq. 7 can be simplified to:

$$
K_{\mathrm{MH}_{r} \mathrm{EDTA}^{(r-2)}} \cdot\left[\mathrm{H}_{r} \operatorname{EDTA}^{(r-4)}\right]=\frac{\lambda}{D}-1
$$

Thus, the apparent stability constants of the $\mathrm{MH}_{r} \mathrm{EDTA}^{(r-2)}$ complexes can be determined using linear regression.

The $\left[\mathrm{H}_{r} \mathrm{EDTA}^{(r-4)}\right]$ term in Eq. 8 refers to the free concentration of the ligand. However, EDTA also forms strong complexes with $\mathrm{Na}^{+}$, which was used as part of the ionic medium. The $\mathrm{Na}^{+}$concentration was considerably higher than the $\mathrm{M}^{2+}$ concentration under all experimental conditions. As a result, the concentration of free EDTA was adjusted by the EDTA complex formation with $\mathrm{Na}^{+}$. The effect of complex formation between EDTA ${ }^{4-}$ or HEDTA ${ }^{3-}$ and $\mathrm{Na}^{+}$has been found to be important [28] and can be described by the following reactions:

$$
\begin{aligned}
\mathrm{Na}^{+}+\mathrm{EDTA}^{4-} & \rightleftharpoons \mathrm{NaEDTA}^{3-} \\
\mathrm{Na}^{+}+\mathrm{HEDTA}^{3-} & \rightleftharpoons \mathrm{NaHEDTA}^{2-}
\end{aligned}
$$

As a result, the free EDTA $^{4-}$ or HEDTA ${ }^{3-}$ concentration in Eq. 8 can be expressed as:

$$
\begin{gathered}
{\left[\mathrm{EDTA}_{\text {free }}^{4-}\right]=\frac{\left[\mathrm{EDTA}_{\mathrm{total}}^{4-}\right]}{1+K^{\mathrm{HEDTA}} \cdot\left[\mathrm{H}^{+}\right]+K^{\mathrm{NaEDTA}} \cdot\left[\mathrm{Na}^{+}\right]}} \\
{\left[\mathrm{HEDTA}_{\text {free }}^{3-}\right]=\frac{\left[\mathrm{EDTA}_{\text {total }}^{4-}\right]}{1+\frac{\left[\mathrm{H}^{+}\right]}{K^{\mathrm{HEDTA}}}+K^{\mathrm{NaHEDTA}} \cdot\left[\mathrm{Na}^{+}\right]}}
\end{gathered}
$$

where $K^{\mathrm{HEDTA}}$ refers to the protonation constant of EDTA ${ }^{4-}$ and $K^{\mathrm{NaEDTA}}$ or $K^{\mathrm{NaHEDTA}}$ refer to the stability constants for reactions 9 and 10 , respectively.

\section{Results and Discussion}

\subsection{Sodium Speciation with EDTA}

The dissociation constant of EDTA and stability constant for reaction 9 have been experimentally studied by many researchers and a comprehensive review is available [26]. The values of the protonation constants and the NaEDTA $^{3-}$ stability constant at zero ionic 
strength were taken from Hummel and co-workers [25] and are listed in Table 1. The SIT ion interaction parameters and associated uncertainties were derived from all available experimental data of $\mathrm{NaEDTA}^{3-}$ and $\mathrm{EDTA}^{4-}$ protonation in $\mathrm{NaCl}$ media at $25{ }^{\circ} \mathrm{C}$ listed in the review [26]. Subsequently, the apparent stability constants were calculated using the derived SIT ion interaction parameters. The apparent EDTA $^{4-}$ protonation constants and $\mathrm{NaEDTA}^{3-}$ stability constants obtained were used to calculate the $\mathrm{Ba}^{2+}$ and $\mathrm{Ra}^{2+}$ stability constants (see Table 5) and free EDTA ${ }^{4-}$ concentration (Eq. 11), respectively. All these stability constants are listed in Table 1.

Only a few experimental data for the formation of the NaHEDTA ${ }^{2-}$ complex (Eq. 10) are available in the literature and the reported $\log _{10} K^{\circ}$ values vary significantly from 0 to 1.5 [29-32]. The main reason for the $\log _{10} K^{\circ}$ data discrepancies is that the NaHEDTA ${ }^{2-}$ complex is quite weak. In the case of weak complex formation, it is usually impossible to separate the weak complex formation effect from potential activity coefficient changes. This and other challenges associated with the determination of the stability constants of weak complexes have been previously discussed in detail [33, 34]. Perhaps, the most reasonable value for the stability constant of the NaHEDTA ${ }^{2-}$ complex was reported by Palaty [31]. The author used ion selective electrodes to study the proton dissociation reactions of EDTA and the sodium-EDTA equilibrium and the obtained stability constant values are in good agreement with the values listed in Table 1 (11.34, 6.81 and 2.61, respectively [31]). Tetramethylammonium chloride was used as the background electrolyte with a total ionic strength of $0.12 \mathrm{~mol} \cdot \mathrm{L}^{-1}$. The temperature was not given by the author [31] but based on all the obtained values it can be assumed that the reported equilibria were studied at $25{ }^{\circ} \mathrm{C}$. The reported value for the $\log _{10} K^{\circ}$ value of the NaHEDTA ${ }^{2-}$ complex was -0.03 . The value is subject to some uncertainty and it is assumed that the actual $\log _{10}$ $K^{\circ}$ value at zero ionic strength lies in the range from -0.5 to 0.5 (i.e., $\log _{10} K=0 \pm 0.5$ ). Most probably, the assignment of such a high, but reasonable, uncertainty for the stability constant of a weak complex is the only way to overcome the lack of reliable data. The proposed $\log _{10} K^{\circ}$ value of $0 \pm 0.5$ is in accord with the statement made by Marcus and

Table 1 Stability constants and SIT ion interaction parameters at $25{ }^{\circ} \mathrm{C}$ used in this work

\begin{tabular}{llll}
\hline Equilibrium reaction & $\begin{array}{l}I_{m} \\
\left(\mathrm{~mol} \cdot \mathrm{kg}^{-1}\right)\end{array}$ & $\begin{array}{l}\text { Stability } \\
\text { constant } \log _{10} K\end{array}$ & $\begin{array}{l}\text { Specific ion interaction parameters } \\
(\mathrm{NaCl}) \Delta \varepsilon\left(\mathrm{mol}^{-1} \mathrm{~kg}^{-1}\right)\end{array}$ \\
\hline $\mathrm{H}^{+}+\mathrm{HEDTA}^{3-} \rightleftharpoons \mathrm{H}_{2} \mathrm{EDTA}^{2-}$ & 0 & $6.80 \pm 0.02$ & $0.40 \pm 0.03$ \\
$\mathrm{H}^{+}+\mathrm{EDTA}^{4-} \rightleftharpoons \mathrm{HEDTA}^{3-}$ & 0 & $11.24 \pm 0.03$ & $0.55 \pm 0.04$ \\
& 0.22 & $10.24 \pm 0.03$ & \\
& 0.51 & $10.12 \pm 0.03$ & \\
& 1.02 & $10.21 \pm 0.04$ & \\
& 2.09 & $10.51 \pm 0.06$ & \\
& 2.64 & $10.74 \pm 0.08$ & \\
$\mathrm{Na}^{+}+\mathrm{EDTA}^{4-} \rightleftharpoons \mathrm{NaEDTA}^{3-}$ & 0 & $2.80 \pm 0.20$ & $0.27 \pm 0.33$ \\
& 0.22 & $1.74 \pm 0.22$ & \\
& 0.51 & $1.54 \pm 0.31$ & \\
& 1.02 & $1.44 \pm 0.52$ & \\
& 2.09 & $1.51 \pm 1.0$ & \\
2.64 & $1.59 \pm 1.3$ & \\
\hline
\end{tabular}


Hefter in relation to $\log _{10} K^{\circ}$ values less than 1, where substantial care needs to be taken in obtaining the exact magnitude of such constants by either experiment or theory [34].

To be able to extrapolate the $\log _{10} K^{\circ}$ value of $0 \pm 0.5$ for the NaHEDTA ${ }^{2-}$ complex at the ionic strengths used in this work, it is necessary to know the following SIT interaction parameters: $\varepsilon\left(\mathrm{Na}^{+}, \mathrm{Cl}^{-}\right), \varepsilon\left(\mathrm{Na}^{+}, \mathrm{HEDTA}^{3-}\right)$ and $\varepsilon\left(\mathrm{Na}^{+}, \mathrm{NaHEDTA}^{2-}\right)$. The first two parameters, with their associated uncertainties, are available in the literature $[25,26]$ and to the best of our knowledge the last parameter has never been reported. A comparison of the sodium SIT ion interactions with many different negatively charged ligands shows that this parameter usually varies from -0.3 to 0.1 [25] (the sodium ion with a divalent anion). Moreover, the sodium SIT ion interaction with ligands similar to $\mathrm{H}_{2} \mathrm{EDTA}^{2-}$ is -0.37 [26]. Consequently, based on these values, the $\varepsilon\left(\mathrm{Na}^{+}, \mathrm{NaHEDTA}^{2-}\right)$ SIT parameter has been estimated as $-(0.2 \pm 0.3) \mathrm{kg} \cdot \mathrm{mol}^{-1}$. All the parameters associated with the NaHEDTA $^{2-}$ complex (Eq. 10) used in this work are listed in Table 2.

\subsection{Stability Constants for the Complex Formation of $\mathrm{Ba}^{2+}$ and $\mathrm{Ra}^{2+}$ with EDTA}

The apparent stability constants for the BaEDTA ${ }^{2-}$ and RaEDTA ${ }^{2-}$ complexes were obtained from distribution coefficients (from experiments conducted at a $-\log _{10}\left[\mathrm{H}^{+}\right]$of 12.4) using a weighted linear regression $\left(\omega_{i}=\sigma_{i}\right)$ with a zero intercept (Eq. 8). The free EDTA $^{4-}$ concentrations were obtained by correcting for the formation of the NaEDTA ${ }^{3-}$ complex (Eq. 9) using Eq. 11 and the values which are listed in Table 1. The standard deviations of the free EDTA ${ }^{4-}$ concentrations were propagated from the standard deviation of the apparent NaEDTA ${ }^{3-}$ stability constants, also listed in Table 1 . The standard deviations of the distribution ratio without the ligand $(\lambda)$ and the distribution ratio with the ligand $(D)$ were calculated based on duplicate series (biased standard deviation with $(n-1)$ in the denominator) and were propagated to the standard deviations of $(\lambda / D-1)$. Standard uncertainty propagation was used in the both cases.

The uncertainties in the linear fitting were obtained using the method of Allard and Ekberg [35]. After obtaining the uncertainties in both the $(\lambda / D-1)$ term and the free EDTA concentration, 30 points were sampled from each uncertainty space using a normal distribution with the mean and standard deviation obtained. Thus, the obtained simulated data points covered the entire standard deviation region in both $x$ and $y$ forming confidence ellipses for each point. Negative simulated values of the free EDTA $^{4-}$ concentrations were

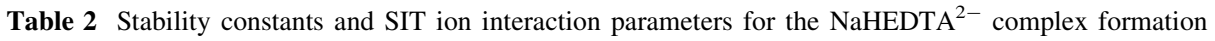
(Eq. 2) at $25^{\circ} \mathrm{C}$

\begin{tabular}{|c|c|c|}
\hline Parameter & Value & References \\
\hline $\log _{10} K^{\circ}$ & $0 \pm 0.5$ & $\begin{array}{l}\text { Estimated in this work, based on available } \\
\text { experimental data from Palaty [31] }\end{array}$ \\
\hline$\varepsilon\left(\mathrm{Na}^{+}, \mathrm{Cl}^{-}\right)$ & $0.03 \pm 0.01\left(\mathrm{~kg} \cdot \mathrm{mol}^{-1}\right)$ & Guillaumont et al. [25] \\
\hline$\varepsilon\left(\mathrm{Na}^{+}, \mathrm{HEDTA}^{3-}\right)$ & $-(0.1 \pm 0.14)\left(\mathrm{kg} \cdot \mathrm{mol}^{-1}\right)$ & Hummel et al. [26] \\
\hline$\varepsilon\left(\mathrm{Na}^{+}, \mathrm{NaHEDTA}^{2-}\right)$ & $-(0.2 \pm 0.3)\left(\mathrm{kg} \cdot \mathrm{mol}^{-1}\right)$ & Estimated in this work \\
\hline
\end{tabular}


discarded. All these points were then used for the linear regression and the estimation of the associated uncertainty analysis.

Figure 1 shows a representative dataset for the linear regression of the BaEDTA ${ }^{2-}$ (reaction 1) apparent stability constant in $0.22 \mathrm{~mol} \cdot \mathrm{kg}^{-1} \mathrm{NaCl}$.

As can be observed from Fig. 1, the standard deviations of the free EDTA ${ }^{4-}$ concentrations are large and increase with an increase in ionic strength $(\mathrm{NaCl})$. These large standard deviations are a consequence of the error propagation that results principally from the large uncertainties in the NaEDTA ${ }^{3-}$ stability constants (Table 1).

The stability constants obtained are listed in Table 3 and extrapolation of the BaEDTA $^{2-}$ and RaEDTA ${ }^{2-}$ stability constants to zero ionic strength (non-weighted linear regression) using the SIT are shown in Fig. 2.

As can be observed from Fig. 2, the fits are satisfactory and the experimental data are accurately modelled by the SIT. According to the calculations, the effect of $\mathrm{Na}^{+}$complex

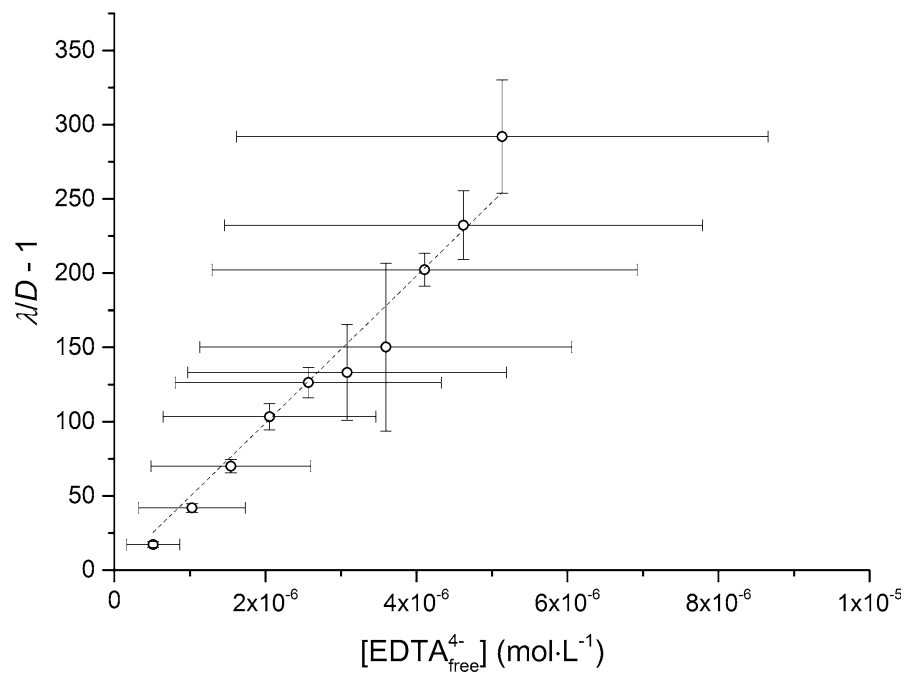

Fig. 1 Determination of BaEDTA ${ }^{2-}$ apparent stability constants using linear regression $\left(0.22 \mathrm{~mol} \cdot \mathrm{kg}^{-1}\right.$ $\mathrm{NaCl}$, reaction 1, Eq. 8)

Table 3 Apparent stability constants of $\mathrm{BaEDTA}^{2-}$ and $\mathrm{RaEDTA}^{2-}$ aqueous complexes in $\mathrm{NaCl}$ media at $25{ }^{\circ} \mathrm{C}$ formed via reaction 1

\begin{tabular}{lll}
\hline$I_{m}\left(\mathrm{~mol} \cdot \mathrm{kg}^{-1}\right)$ & $\log _{10} K_{\text {BaEDTA }}$ & $\log _{10} K_{\text {RaEDTA }}$ \\
\hline 0 & $9.88 \pm 0.11$ & $9.11 \pm 0.09$ \\
0.22 & $7.70 \pm 0.08$ & $6.96 \pm 0.20^{\mathrm{a}}$ \\
0.51 & $7.38 \pm 0.08$ & $6.60 \pm 0.08$ \\
1.02 & $6.99 \pm 0.12$ & $6.42 \pm 0.10$ \\
2.09 & $7.10 \pm 0.08$ & $6.60 \pm 0.10$ \\
2.64 & $7.16 \pm 0.08$ & $6.63 \pm 0.08$ \\
\hline
\end{tabular}

Ionic strengths were adjusted from the $\mathrm{mol} \cdot \mathrm{L}^{-1}$ to $\mathrm{mol} \cdot \mathrm{kg}^{-1}$ scale using the appropriate conversion factors [25]. Uncertainties correspond to $95 \%$ confidence intervals

${ }^{a}$ Estimated uncertainty 


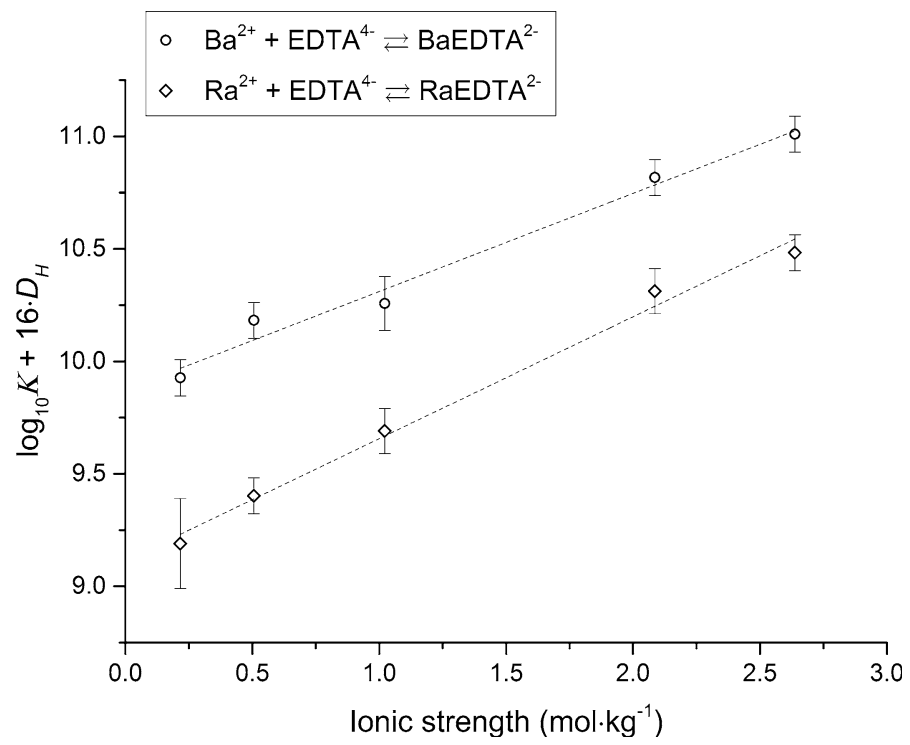

Fig. 2 Extrapolation of BaEDTA ${ }^{2-}$ and $\mathrm{RaEDTA}^{2-}$ apparent stability constants $(\mathrm{NaCl}$ media, reaction 1$)$ to zero ionic strength using SIT

formation with $\mathrm{EDTA}^{4-}$ (Eq. 9) is significant and the difference between the corrected and uncorrected stability constants of both BaEDTA ${ }^{2-}$ and RaEDTA $^{2-}$ at zero ionic strength is more than $1 \log _{10}$ unit. The difference between the slopes (with and without correction for Na complex formation with EDTA), which corresponds to the ion interaction parameter term, was also significant and the deviation of the experimental data points from the regression line was higher at increased ionic strength. This strongly indicates that the complex formation between sodium and EDTA is significant, which is in agreement with previous studies [28].

The apparent stability constants, assuming only the formation of the $\mathrm{BaHEDTA}^{-}$and RaHEDTA $^{-}$complexes [according to reaction $1(r=1)$ ], were derived from the experiments conducted at $-\log _{10}\left[\mathrm{H}^{+}\right]$of $7.9-8.3$ with the mole fraction of HEDTA ${ }^{3-}$ being more than $98 \%$ using the same method as used for derivation of the BaEDTA $^{2-}$ and RaEDTA $^{2-}$ complex stability constants. The apparent stability constants obtained were extrapolated to zero ionic strength using the SIT that resulted in stability constants of $\log _{10}$ $K^{\circ}=7.34 \pm 0.30$ (for BaHEDTA ${ }^{-}$) and $\log _{10} K^{\circ}=6.57 \pm 0.30$ (for RaHEDTA ${ }^{-}$). Schwarzenbach and Ackermann [36] have previously given a $\log _{10} K$ value for the same reaction (BaHEDTA ${ }^{-}$complex) of 2.07 at $20{ }^{\circ} \mathrm{C}$ and an ionic strength of $0.1 \mathrm{~mol} \cdot \mathrm{L}^{-1}$. This value, when extrapolated to zero ionic strength, results in $\log _{10} K^{\circ}=3.15$, which is much lower than the value obtained in the present work. It can be seen that the value from this study is more than four orders of magnitude larger than the value given by Schwarzenbach and Ackermann. There are two probable reasons for the disagreement between these two values: either the assumption that the $\mathrm{BaHEDTA}^{-}$complex is formed according to reaction $1(r=1)$ at $-\log _{10}\left[\mathrm{H}^{+}\right]$of $7.9-8.3$ is not valid or the data from Schwarzenbach and Ackermann are inconsistent. The latest hypothesis can be verified by combining the data from Schwarzenbach and Ackermann [36] with other literature data $[37,38]$, where the stability constants for the reaction of various metals with EDTA ${ }^{4-}$ and HEDTA $^{3-}$ are reported for the same experimental conditions $\left(20{ }^{\circ} \mathrm{C}\right.$ and an ionic strength 
of $0.1 \mathrm{~mol} \cdot \mathrm{L}^{-1}$ ) and performing a linear free energy analysis of the data. This analysis (i.e., a plot of the $\log _{10} K$ values of $\mathrm{M}^{n+}$ EDTA $^{4-}$ complexes against the $\log _{10} K$ of $\mathrm{M}^{n+}$ HEDTA $^{3-}$ complexes, where $\mathrm{M}^{n+}$ is a metal ion with $n \geq 2$ (reaction 1 with $r=0$ and $r=1$, respectively)) is shown in Fig. 3 .

As shown in Fig. 3, there is a strong relationship between the magnitude $\left(\log _{10} K\right.$ values) of the $\mathrm{M}^{n+} \operatorname{EDTA}^{(4-n)}$ and $\mathrm{M}^{n+} \operatorname{HEDTA}^{(3-n)}$ stability constants $(n \geq 2)$, and consequently, the available literature data [36-38] are consistent. Therefore, the assumption that only the $\mathrm{BaHEDTA}^{-}$or RaHEDTA ${ }^{-}$complexes are formed at a $-\log _{10}\left[\mathrm{H}^{+}\right]$of $7.9-8.3$ is not valid. The stability constant for the BaHEDTA ${ }^{-}$complex derived in the present study is more than four orders of magnitude larger when compared to those values available in the literature, which indicates that another stronger complex dominates at a $-\log _{10}\left[\mathrm{H}^{+}\right]$of 7.9-8.3. The only other strong complex that could be formed in the studied system is BaEDTA $^{2-}$ (or RaEDTA ${ }^{2-}$ ). The likely mechanism of the formation of these two complexes at a $-\log _{10}\left[\mathrm{H}^{+}\right]$of 7.9-8.3, where the mole fraction of HEDTA ${ }^{3-}$ is more than $98 \%$ is as follows:

$$
\begin{aligned}
& \mathrm{Ba}^{2+}+\mathrm{HEDTA}^{3-} \rightleftharpoons \mathrm{BaEDTA}^{2-}+\mathrm{H}^{+} \\
& \mathrm{Ra}^{2+}+\mathrm{HEDTA}^{3-} \rightleftharpoons \mathrm{RaEDTA}^{2-}+\mathrm{H}^{+}
\end{aligned}
$$

If the proposed reactions 13 and 14 occur in the studied system, then Eq. 7 can be adapted to reactions 13 and 14 to describe the experimental data obtained at a $-\log _{10}\left[\mathrm{H}^{+}\right]$of $7.9-$ 8.3:

$$
K_{\mathrm{M}_{r} \operatorname{EDTA}^{(r-4)}} \cdot \frac{\left[\operatorname{HEDTA}^{3-}\right]}{\left[\mathrm{H}^{+}\right]}=\frac{\lambda}{D}-1
$$

According to Eq. 15, the concentration of the free HEDTA ${ }^{3-}$ must be divided by the $\mathrm{H}^{+}$ concentration to obtain the apparent stability constant for the BaEDTA ${ }^{2-}$ or RaEDTA ${ }^{2-}$

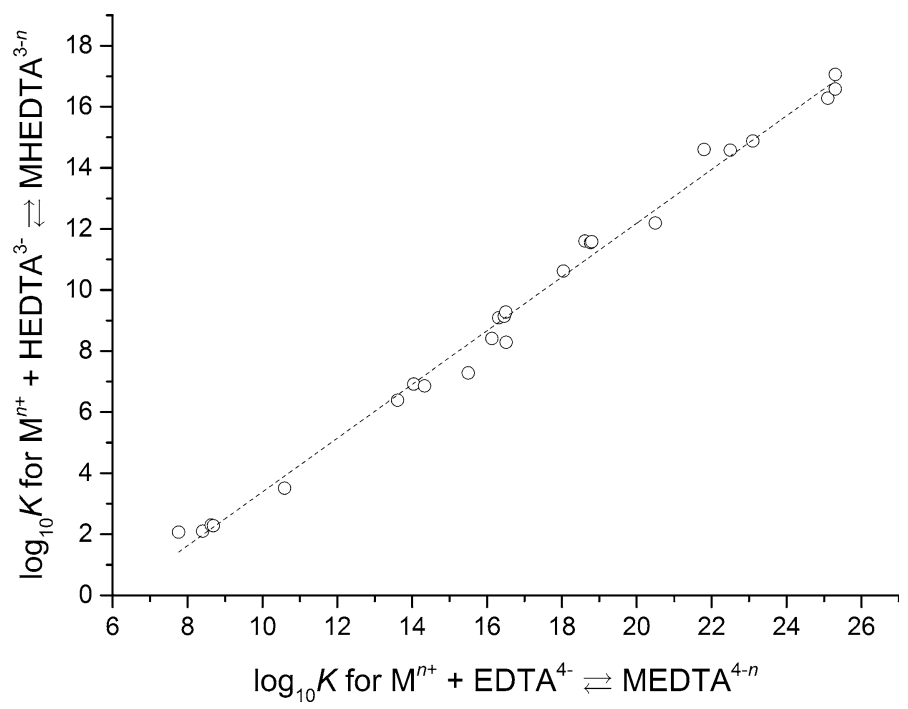

Fig. 3 Linear free energy analysis of available literature data [36-38] for the decadic logarithm of $\mathrm{M}^{n+} \operatorname{EDTA}^{(4-n)}$ and $\mathrm{M}^{n+} \operatorname{HEDTA}^{(3-n)}$ apparent stability constants $(n \geq 2)$ at the same experimental conditions $\left(20{ }^{\circ} \mathrm{C}, I=0.1 \mathrm{~mol} \cdot \mathrm{L}^{-1}\right)$ 
Table 4 Apparent stability constants of $\mathrm{BaEDTA}^{2-}$ and $\mathrm{RaEDTA}^{2-}$ aqueous complexes in $\mathrm{NaCl}$ media at $25^{\circ} \mathrm{C}$ formed via reactions 13 and 14 and 1

\begin{tabular}{lllll}
\hline $\begin{array}{l}I_{m} \\
\left(\mathrm{~mol} \cdot \mathrm{kg}^{-1}\right)\end{array}$ & $\begin{array}{l}\log _{10} K_{\mathrm{BaEDTA}} \\
\text { (formed via } \\
\text { reaction 13) }\end{array}$ & $\begin{array}{l}\log _{10} K_{\mathrm{BaEDTA}} \\
\text { formed via } \\
\text { reaction 1) }\end{array}$ & $\begin{array}{l}\log _{10} K_{\mathrm{RaEDTA}} \\
\text { formed via } \\
\text { reaction 14) }\end{array}$ & $\begin{array}{l}\log _{10} K_{\mathrm{RaEDTA}} \\
\text { formed via } \\
\text { reaction 1) }\end{array}$ \\
\hline 0 & $-1.41 \pm 0.12$ & $9.83 \pm 0.14$ & $-2.07 \pm 0.11$ & $9.17 \pm 0.13$ \\
0.22 & $-2.63 \pm 0.06$ & $7.61 \pm 0.08$ & $-3.26 \pm 0.06$ & $6.98 \pm 0.08$ \\
0.51 & $-2.80 \pm 0.08$ & $7.32 \pm 0.10$ & $-3.42 \pm 0.08$ & $6.71 \pm 0.10$ \\
1.02 & $-3.21 \pm 0.08$ & $7.00 \pm 0.11$ & $-3.85 \pm 0.08$ & $6.37 \pm 0.11$ \\
2.09 & $-3.49 \pm 0.08$ & $7.02 \pm 0.14$ & $-4.15 \pm 0.10$ & $6.36 \pm 0.15$ \\
2.64 & $-3.75 \pm 0.08$ & $6.99 \pm 0.18$ & $-4.24 \pm 0.08$ & $6.50 \pm 0.18$ \\
\hline
\end{tabular}

Ionic strengths were adjusted from the $\mathrm{mol} \cdot \mathrm{L}^{-1}$ to $\mathrm{mol} \cdot \mathrm{kg}^{-1}$ scale using the appropriate conversion factors [25] and $\log _{10} K_{\mathrm{BaEDTA}}$ or $\log _{10} K_{\mathrm{RaEDTA}}$ for the reactions 13 and 14 were calculated using EDTA ${ }^{4-}$ protonation constants listed in Table 1 . Uncertainties correspond to $95 \%$ confidence interval

complex via reactions 13 and 14 under these lower $-\log _{10}\left[\mathrm{H}^{+}\right]$conditions. Moreover, it can be shown that the sum of the decadic logarithm of obtained stability constants for reactions 13 and 14 and the decadic logarithm of the protonation constant of EDTA ${ }^{4-}$ results in the decadic logarithm of the stability constant for the BaEDTA $^{2-}$ or RaEDTA ${ }^{2-}$ complexes formed via reaction 1 with $r=0$. The stability constants for reactions 13 and 14 at a $-\log _{10}\left[\mathrm{H}^{+}\right]$of $7.9-8.3$ and the associated standard deviations were derived using the same method as was used to derive stability constants and standard deviations for reaction 1 with $r=0$ at a $-\log _{10}\left[\mathrm{H}^{+}\right]$of 12.4 . These stability constants and the calculated stability constants for reaction 1 with $r=0$, using the derived constants and the protonation constants of $\mathrm{EDTA}^{4-}$ from Table 1, are listed in Table 4. Extrapolation of the BaEDTA $^{2-}$ and RaEDTA ${ }^{2-}$ stability constants to zero ionic strength using the SIT is shown in Fig. 4.

As can be observed in Fig. 4, the experimental data are accurately described by Eq. 15. A comparison of the stability constants of the BaEDTA ${ }^{2-}$ and RaEDTA ${ }^{2-}$ complexes formed via reaction 1 listed in Table 4 with the same stability constants listed in Table 3 shows that all the values are within the $95 \%$ confidence intervals. This strongly indicates that the proposed reactions 13 and 14 occur at the $\mathrm{pH}$ region where the HEDTA ${ }^{3-}$ species dominates. The effect of $\mathrm{Na}^{+}$complex formation with $\mathrm{HEDTA}^{3-}$ (Eq. 10) was not as significant as in the case of EDTA ${ }^{4-}$ due to the fact that the NaHEDTA ${ }^{2-}$ complex is much weaker than NaEDTA ${ }^{3-}$ (Tables 1, 2).

A comparison of the average value of the obtained metal-EDTA stability constants at zero ionic strength with data available in the literature is shown in Table 5. The data from the literature were, where necessary, extrapolated to zero ionic strength using the Davies equation [39] (in the last term $0.2 \cdot I$ was used instead of $0.3 \cdot I$, the latter as proposed by Davies [40]) for activity coefficient corrections. The weighted mean and associated $95 \%$ confidence intervals of the BaEDTA ${ }^{2-}$ and RaEDTA $^{2-}$ stability constants at zero ionic strength were calculated from the values listed in Tables 3 and 4.

Experimental data for the stability constant of BaEDTA ${ }^{2-}[36,41-46]$ and reviews of relevant stability constants $[38,51]$ are available in the literature. The data given in Table 5 for extrapolation of the literature data for the stability constant of $\mathrm{BaEDTA}^{2-}$ to zero ionic strength are in very good agreement with the value determined in the present work. 


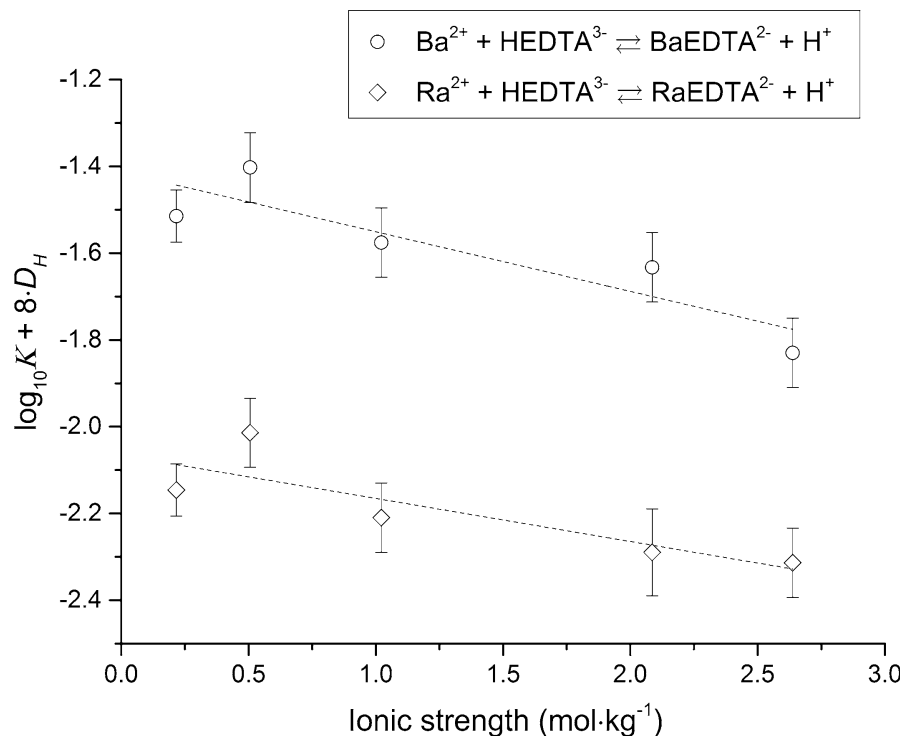

Fig. 4 Extrapolation of BaEDTA ${ }^{2-}$ and $\mathrm{RaEDTA}^{2-}$ apparent stability constants $(\mathrm{NaCl}$ media, reactions 13 and 14) to zero ionic strength using the SIT

The complex formation of radium with EDTA has been studied by several researchers using the ion exchange or solvent extraction methods and the experimental data have been reviewed $[51,52]$. Nikolsky and co-workers were the first to study RaEDTA ${ }^{2-}$ complex formation and obtained a $\log _{10} K$ value of 7.12 for $\operatorname{RaEDTA}^{2-}$ [47]. The value was extrapolated to zero ionic strength assuming a temperature of $20{ }^{\circ} \mathrm{C}$ and an ionic strength of $0.1 \mathrm{~mol} \cdot \mathrm{L}^{-1}$. Baetsle and Bengsch studied RaEDTA ${ }^{2-}$ complex formation using an ion exchange resin (Amberlite IR120) at $20{ }^{\circ} \mathrm{C}$ and an ionic strength of $0.1 \mathrm{~mol} \cdot \mathrm{L}^{-1}$ (sodium salt) and reported a $\log _{10} K$ value of $7.07 \pm 0.06$ [48]. The concentration of EDTA ${ }^{4-}$ was $0.01 \mathrm{~mol} \cdot \mathrm{L}^{-1}$ and an acetate buffer was used. Such a high concentration of EDTA ${ }^{4-}$ has a significant influence on the ionic strength, and therefore, the actual ionic strength used was $0.19 \mathrm{~mol} \cdot \mathrm{L}^{-1}$ and this value has been used to extrapolate the reported value to zero ionic strength. Sekine and co-workers used solvent extraction (a mixture of $0.1 \mathrm{~mol} \cdot \mathrm{L}^{-1}$ thenoyltrifluoroacetone and $0.1 \mathrm{~mol} \cdot \mathrm{L}^{-1}$ tributylphosphate in $\mathrm{CCl}_{4}$ ) to study $\mathrm{Ra}^{2+}$ complex formation with various amino carboxylic acids at $25{ }^{\circ} \mathrm{C}$ and $0.1 \mathrm{~mol} \cdot \mathrm{L}^{-1} \mathrm{NaClO}_{4}$ and obtained a $\log _{10} K$ value of 7.7 for the RaEDTA ${ }^{2-}$ complex [49]. A $\log _{10} K$ value for RaEDTA $^{2-}$ was also estimated to be 7.4 for $25{ }^{\circ} \mathrm{C}$ and an ionic strength of $0.1 \mathrm{~mol} \cdot \mathrm{L}^{-1}$ by Nelson and co-workers [50]. The RaEDTA ${ }^{2-}$ stability constant obtained in this work is in very good agreement with those of the other studies when taking into account differences in temperature, ionic strength and difficulties in analyzing the literature data (experimental details missing, high EDTA concentrations affecting the ionic media etc.). Probably the best comparison of the RaEDTA ${ }^{2-}$ stability constants obtained in this work is with work of Sekine and co-workers and values obtained for zero ionic strength from the two studies are in very good agreement.

The difference between $\log _{10} K_{\text {BaEDTA }}^{\circ 2-}$ and $\log _{10} K_{\text {RaEDTA }}^{\circ 2-}$ is $0.73 \log _{10}$ units. The difference is relatively small which may indicate that the speciation of $\mathrm{Ba}^{2+}, \mathrm{Ra}^{2+}$, and potentially other alkaline earth metals with $\mathrm{EDTA}^{4-}$, depends on the ionic radius of the 
Table 5 Comparison of reported stability constants for the formation of BaEDTA ${ }^{2-}$ and RaEDTA ${ }^{2-}$

\begin{tabular}{|c|c|c|c|c|c|}
\hline Method & Ionic medium & $\begin{array}{l}\text { Temperature } \\
\left({ }^{\circ} \mathrm{C}\right)\end{array}$ & $\begin{array}{l}\text { Reported } \\
\log _{10} K\end{array}$ & $\begin{array}{l}\text { Extrapolated } \\
\text { to zero ionic } \\
\text { strength } \log _{10} \\
K^{\circ}\end{array}$ & Reference \\
\hline \multicolumn{6}{|c|}{$\mathrm{Ba}^{2+}+\mathrm{EDTA}^{4-} \leftrightharpoons \mathrm{BaEDTA}^{2-}$} \\
\hline Ion exchange & $\begin{array}{l}0.2 ; 0.5 ; 1.0 ; 2.0 \\
\quad 2.5 \mathrm{~mol} \cdot \mathrm{L}^{-1} \\
(\mathrm{NaCl})\end{array}$ & 25 & $\begin{array}{l}\text { Tables } 3 \text { and } \\
4\end{array}$ & $9.86 \pm 0.09$ & This work \\
\hline Review & $0.1 \mathrm{~mol} \cdot \mathrm{L}^{-1}$ & 25 & $7.86 \pm 0.08$ & 9.64 & $\begin{array}{l}\text { Smith and } \\
\text { Martell [38] }\end{array}$ \\
\hline $\mathrm{pH}$ & $\begin{array}{l}0.1 \mathrm{~mol} \cdot \mathrm{L}^{-1} \\
(\mathrm{KCl})\end{array}$ & 20 & 7.76 & 9.54 & $\begin{array}{l}\text { Schwarzenbach } \\
\text { and } \\
\text { Ackermann } \\
\text { [36] }\end{array}$ \\
\hline $\mathrm{pH}$ & $0.1 \mathrm{~mol} \cdot \mathrm{L}^{-1 \text { a }}$ & 25 & 7.73 & 9.51 & $\begin{array}{l}\text { Carini and } \\
\text { Martell [41] }\end{array}$ \\
\hline $\mathrm{pH}$ & $0.1 \mathrm{~mol} \cdot \mathrm{L}^{-1}$ & 25 & 7.9 & 9.68 & $\begin{array}{l}\text { Schmid and } \\
\text { Reilley [42] }\end{array}$ \\
\hline Ion exchange & 0 & 25 & 9.92 & 9.92 & $\begin{array}{l}\text { Astakhov and } \\
\text { Fomenko [43] }\end{array}$ \\
\hline $\mathrm{pH}$ & $\begin{array}{c}0.1 \mathrm{~mol} \cdot \mathrm{L}^{-1} \\
\left(\mathrm{KNO}_{3}\right)\end{array}$ & 25 & 7.63 & 9.41 & $\begin{array}{l}\text { Bohigian and } \\
\text { Martell [44] }\end{array}$ \\
\hline $\begin{array}{l}\text { Paper } \\
\text { electrophoresis }\end{array}$ & $\begin{array}{c}0.1 \mathrm{~mol} \cdot \mathrm{L}^{-1} \\
\left(\mathrm{KNO}_{3}\right)\end{array}$ & 20 & 8 & 9.78 & $\begin{array}{l}\text { Jokl and Majer } \\
\text { [45] }\end{array}$ \\
\hline $\mathrm{pH}$ & $\begin{array}{l}0.1 \mathrm{~mol} \cdot \mathrm{L}^{-1} \\
\quad\left(\mathrm{KNO}_{3} \text { or }\right. \\
\left.\left(\mathrm{CH}_{3}\right)_{4} \mathrm{~N}\left(\mathrm{NO}_{3}\right)\right)\end{array}$ & 25 & 7.8 & 9.58 & $\begin{array}{l}\text { Delgado and } \mathrm{Da} \\
\text { Silva [46] }\end{array}$ \\
\hline \multicolumn{6}{|c|}{$\mathrm{Ra}^{2+}+\mathrm{EDTA}^{4-} \leftrightharpoons \mathrm{RaEDTA}^{2-}$} \\
\hline Ion exchange & $\begin{array}{l}0.2 ; 0.5 ; 1 ; 2 ; \\
2.5 \mathrm{~mol} \cdot \mathrm{L}^{-1} \\
(\mathrm{NaCl})\end{array}$ & 25 & Table 3 & $9.13 \pm 0.07$ & This work \\
\hline Ion exchange & $0.1 \mathrm{~mol} \cdot \mathrm{L}^{-1 \mathrm{a}}$ & $20^{\mathrm{a}}$ & 7.12 & 8.9 & $\begin{array}{l}\text { Nikolsky et al. } \\
\text { [47] }\end{array}$ \\
\hline Ion exchange & $\begin{array}{l}0.1 \mathrm{~mol} \cdot \mathrm{L}^{-1} \mathrm{~b} \\
\quad \text { (sodium salt) }\end{array}$ & 20 & $7.07^{\mathrm{b}} \pm 0.06$ & $9.22^{\mathrm{b}}$ & $\begin{array}{l}\text { Baetsle and } \\
\text { Bengsch [48] }\end{array}$ \\
\hline $\begin{array}{l}\text { Solvent } \\
\text { extraction }\end{array}$ & $\begin{array}{c}0.1 \mathrm{~mol} \cdot \mathrm{L}^{-1} \\
\left(\mathrm{NaClO}_{4}\right)\end{array}$ & 25 & 7.7 & 9.29 & $\begin{array}{l}\text { Sekine et al. } \\
\text { [49] }\end{array}$ \\
\hline Estimated & $0.1 \mathrm{~mol} \cdot \mathrm{L}^{-1}$ & 25 & 7.4 & 9.2 & $\begin{array}{l}\text { Nelson et al. } \\
{[50]}\end{array}$ \\
\hline
\end{tabular}

${ }^{a}$ Ionic strength and temperature were assumed

${ }^{\mathrm{b}}$ Contribution of the $0.01 \mathrm{~mol} \cdot \mathrm{L}^{-1}$ EDTA to the total ionic strength has been considered

metal ion. Extrapolation of the thermodynamic properties of radium, including stability constants, from the property values of other alkaline-earth metals using an electrostatic model is a widely used method [8]. A plot of the decadic logarithm of stability constants of calcium (taken from [26]), strontium (taken from [38] and extrapolated to zero ionic strength using the Davies equation), barium and radium with EDTA $^{4-}$ at zero ionic strength and $25{ }^{\circ} \mathrm{C}$ against the effective ionic radii of these elements in 8-fold coordination (taken from Shannon [15]) is shown in Fig. 5. 


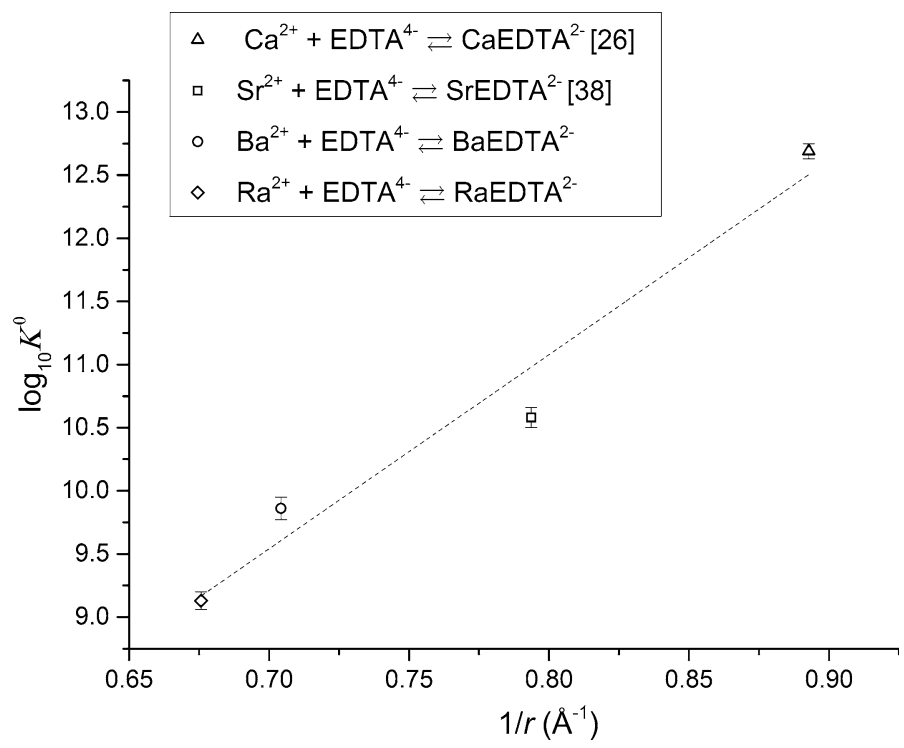

Fig. 5 Comparison of alkaline-earth metal-EDTA ${ }^{4-}$ stability constants at zero ionic strength using their effective ionic radii in 8-fold coordination (ionic radii taken from Shannon [15])

As shown in Fig. 5, the fit is good for all alkaline-earth metals which likely indicates that the bonding between these alkaline-earth metals and EDTA $^{4-}$ is similar and relativistic or other effects do not occur. It also confirms that the electrostatic model is a useful tool for extrapolation of radium thermodynamic properties and obtaining a first estimate of stability constants for radium complexation.

\subsection{SIT Ion Interaction Parameters of $\mathrm{Ba}^{2+}$ and $\mathrm{Ra}^{2+}$}

According to the SIT model (Eq. 5), the slopes are equal to the ion interaction parameters between oppositely charged ions. The slopes for the extrapolation to zero ionic strength in Figs. 1 and 3 yield the SIT ion interaction parameter terms shown in Eqs. 16, 17, 18, and 19, respectively:

$$
\begin{gathered}
\Delta \varepsilon_{1}^{\text {BaEDTA }}=\varepsilon\left(\mathrm{Na}^{+}, \mathrm{BaEDTA}^{2-}\right)-\varepsilon\left(\mathrm{Ba}^{2+}, \mathrm{Cl}^{-}\right)-\varepsilon\left(\mathrm{Na}^{+}, \mathrm{EDTA}^{4-}\right) \\
\Delta \varepsilon_{1}^{\mathrm{RaEDTA}}=\varepsilon\left(\mathrm{Na}^{+}, \mathrm{RaEDTA}^{2-}\right)-\varepsilon\left(\mathrm{Ra}^{2+}, \mathrm{Cl}^{-}\right)-\varepsilon\left(\mathrm{Na}^{+}, \mathrm{EDTA}^{4-}\right) \\
\Delta \varepsilon_{2}^{\mathrm{BaEDTA}}=\varepsilon\left(\mathrm{Na}^{+}, \mathrm{BaEDTA}^{2-}\right)+\varepsilon\left(\mathrm{H}^{+}, \mathrm{Cl}^{-}\right)-\varepsilon\left(\mathrm{Ba}^{2+}, \mathrm{Cl}^{-}\right)-\varepsilon\left(\mathrm{Na}^{+}, \mathrm{HEDTA}^{3-}\right) \\
\Delta \varepsilon_{2}^{\mathrm{RaEDTA}}=\varepsilon\left(\mathrm{Na}^{+}, \mathrm{RaEDTA}^{2-}\right)+\varepsilon\left(\mathrm{H}^{+}, \mathrm{Cl}^{-}\right)-\varepsilon\left(\mathrm{Ra}^{2+}, \mathrm{Cl}^{-}\right)-\varepsilon\left(\mathrm{Na}^{+}, \mathrm{HEDTA}^{3-}\right)
\end{gathered}
$$

The SIT ion interaction parameters determined for Eqs. 16-19 and some other ion interactions relevant to the studied systems are listed in Table 6 .

As shown in Table 6, the SIT parameters for all of the listed alkaline-earth metal ions are very similar. According to the SIT, interactions occur only between ions of opposite 
Table 6 SIT ion interaction parameters $\mathrm{kg} \cdot \mathrm{mol}^{-1}$ of some metal ions and ligands relevant to the studied systems at $25{ }^{\circ} \mathrm{C}$

\begin{tabular}{lcl}
\hline Interaction & SIT parameters $\left(\mathrm{kg} \cdot \mathrm{mol}^{-1}\right)$ & References \\
\hline$\Delta \varepsilon_{1}\left(\mathrm{MgEDTA}^{2-}\right)$ & $-(0.52 \pm 0.04)$ & {$[26]$} \\
$\Delta \varepsilon_{1}\left(\mathrm{CaEDTA}^{2-}\right)$ & $-(0.5 \pm 0.5)$ & {$[26]$} \\
$\Delta \varepsilon_{1}\left(\mathrm{BaEDTA}^{2-}\right)$ & $-(0.44 \pm 0.07)$ & Equation 16 (this work) \\
$\Delta \varepsilon_{1}\left(\mathrm{RaEDTA}^{2-}\right)$ & $-(0.54 \pm 0.06)$ & Equation 17 (this work) \\
$\Delta \varepsilon_{2}\left(\mathrm{BaEDTA}^{2-}\right)$ & $0.14 \pm 0.08$ & Equation 18 (this work) \\
$\Delta \varepsilon_{2}\left(\mathrm{RaEDTA}^{2-}\right)$ & $0.10 \pm 0.07$ & Equation 19 (this work) \\
$\varepsilon\left(\mathrm{Na}^{+}, \mathrm{EDTA}^{4-}\right)$ & $0.32 \pm 0.14$ & {$[25]$} \\
$\varepsilon\left(\mathrm{Na}^{+}, \mathrm{HEDTA}^{3-}\right)$ & $-(0.10 \pm 0.14)$ & {$[25]$} \\
$\varepsilon\left(\mathrm{H}^{+}, \mathrm{Cl}^{-}\right)$ & $0.12 \pm 0.01$ & {$[25]$} \\
$\varepsilon\left(\mathrm{Ba}^{2+}, \mathrm{Cl}^{-}\right)$ & $0.07 \pm 0.01$ & {$[25]$} \\
$\varepsilon\left(\mathrm{Na}^{+}, \mathrm{MgEDTA}^{2-}\right)$ & $-(0.01 \pm 0.15)$ & {$[25]$} \\
$\varepsilon\left(\mathrm{Na}^{+}, \mathrm{BaEDTA}^{2-}\right)$ & $-(0.03 \pm 0.11)$ & This work \\
$\varepsilon\left(\mathrm{Na}^{+}, \mathrm{RaEDTA}^{2-}\right)$ & $-(0.10 \pm 0.11)^{\mathrm{a}}$ & This work \\
\hline $\left.\mathrm{Un}^{2-}\right)$ &
\end{tabular}

Uncertainties correspond to $95 \%$ confidence interval

${ }^{\mathrm{a}}$ This value has been calculated using $\varepsilon\left(\mathrm{Ba}^{2+}, \mathrm{Cl}^{-}\right)$as a substitute for $\varepsilon\left(\mathrm{Ra}^{2+}, \mathrm{Cl}^{-}\right)$

charge, which means that the alkaline-earth metal ions undergo similar short- and longrange electrostatic interactions with $\mathrm{EDTA}^{4-}$ and $\mathrm{Cl}^{-}$. The SIT ion interaction parameters between $\mathrm{Na}^{+}$and $\mathrm{BaEDTA}^{2-}$ can be calculated as a weighted mean (Eqs. 16 and 18) and using the derived $\Delta \varepsilon_{1}\left(\mathrm{BaEDTA}^{2-}\right)$ or $\Delta \varepsilon_{2}\left(\mathrm{BaEDTA}^{2-}\right)$ and previously established ion interaction parameters: $\varepsilon\left(\mathrm{Ba}^{2+}, \mathrm{Cl}^{-}\right), \varepsilon\left(\mathrm{H}^{+}, \mathrm{Cl}^{-}\right), \varepsilon\left(\mathrm{Na}^{+}, \mathrm{EDTA}^{4-}\right)$ and $\varepsilon\left(\mathrm{Na}^{+}, \mathrm{HEDTA}^{3-}\right)$ [25]. The SIT ion interaction parameters between $\mathrm{Na}^{+}$and $\mathrm{RaEDTA}^{2-}$ can be calculated using the same method, with $\varepsilon\left(\mathrm{Ba}^{2+}, \mathrm{Cl}^{-}\right)$continuing to substitute for $\varepsilon\left(\mathrm{Ra}^{2+}, \mathrm{Cl}^{-}\right)$. All parameters are listed in Table 6 and a comparison of the computed $\varepsilon\left(\mathrm{Na}^{+}, \mathrm{BaEDTA}^{2-}\right)$ and $\varepsilon\left(\mathrm{Na}^{+}, \mathrm{RaEDTA}^{2-}\right)$ parameters with $\varepsilon\left(\mathrm{Na}^{+}, \mathrm{MgEDTA}^{2-}\right)$, taken from the literature [25], shows that all parameters are within the $95 \%$ confidence intervals.

The barium ion interaction parameters are often used as a substitute for the radium parameters due to a lack of experimental data in the case of radium [5, 16, 17]. It is possible to verify this methodology by calculation of $\Delta \varepsilon_{1}\left(\operatorname{RaEDTA}^{2-}\right)$ or $\Delta \varepsilon_{2}\left(\operatorname{RaEDTA}^{2-}\right)$ (Eqs. 17 and 19) using $\varepsilon\left(\mathrm{Na}^{+}, \mathrm{EDTA}^{4-}\right), \varepsilon\left(\mathrm{Na}^{+}, \mathrm{HEDTA}^{3-}\right)$ and the barium SIT parameters listed in Table 6 as substitutes for unknown radium parameters (i.e., $\varepsilon\left(\mathrm{Na}^{+}\right.$, BaEDTA $\left.{ }^{2-}\right)$ instead of $\varepsilon\left(\mathrm{Na}^{+}, \mathrm{RaEDTA}^{2-}\right)$ and $\varepsilon\left(\mathrm{Ba}^{2+}, \mathrm{Cl}^{-}\right)$instead of $\left.\varepsilon\left(\mathrm{Ra}^{2+}, \mathrm{Cl}^{-}\right)\right)$. This results in $\Delta \varepsilon_{1}\left(\operatorname{RaEDTA}^{2-}\right)=-(0.42 \pm 0.18)$ and $\Delta \varepsilon_{2}$ $\left(\right.$ RaEDTA $\left.^{2-}\right)=-(0.08 \pm 0.18)$ which are within the $95 \%$ confidence intervals of the experimentally determined $\Delta \varepsilon_{1}\left(\operatorname{RaEDTA}^{2-}\right)$ and $\Delta \varepsilon_{2}\left(\operatorname{RaEDTA}^{2-}\right)$ SIT parameters. This indicates that the method of using the barium SIT parameters as a substitute for those of radium is valid for the $\mathrm{Ra}^{2+}-\mathrm{NaCl}-\mathrm{EDTA}^{4-}$ system at ionic strengths below $3.5 \mathrm{~mol} \cdot \mathrm{kg}^{-1}$. 


\section{Conclusion}

The apparent stability constants of the BaEDTA $^{2-}$ and RaEDTA $^{2-}$ complexes were determined over a wide range of $\mathrm{NaCl}$ concentrations $\left(0.2-2.5 \mathrm{~mol} \cdot \mathrm{L}^{-1}\right)$ at $25{ }^{\circ} \mathrm{C}$ and in two $\mathrm{pH}$ regions where the EDTA ${ }^{4-}$ and $\mathrm{HEDTA}^{3-}$ species dominate. The obtained constants were extrapolated to zero ionic strength using the SIT and compared with available literature data. It was found that in the $\mathrm{pH}$ region where the $\mathrm{HEDTA}^{3-}$ species dominates, the reaction of $\mathrm{Ba}^{2+}$ or $\mathrm{Ra}^{2+}$ with the HEDTA ${ }^{3-}$ ligand results in the formation of the BaEDTA $^{2-}$ and RaEDTA $^{2-}$ complexes and a proton release and that formation of BaHEDTA $^{-}$or RaHEDTA ${ }^{-}$does not occur in alkaline media. The similarity of the barium and radium ion interaction parameters indicates that both metal ions undergo almost identical short- and long-range electrostatic interactions with $\mathrm{EDTA}^{4-}$ and $\mathrm{Cl}^{-}$. The results also show that using the SIT interaction parameters of $\mathrm{Ba}^{2+}$ as a substitute for missing $\mathrm{Ra}^{2+}$ SIT interaction parameters is a useful tool for the $\mathrm{Ra}^{2+}-\mathrm{NaCl}-\mathrm{EDTA}^{4-}$ system.

Acknowledgements This work has received funding from the Swedish Radiation Protection Authority (SSM). The authors are grateful to Dr. Stellan Holgersson and Dr. Kastriot Spahiu for help with experimental work and valuable discussions.

Open Access This article is distributed under the terms of the Creative Commons Attribution 4.0 International License (http://creativecommons.org/licenses/by/4.0/), which permits unrestricted use, distribution, and reproduction in any medium, provided you give appropriate credit to the original author(s) and the source, provide a link to the Creative Commons license, and indicate if changes were made.

\section{References}

1. Winter, M.: WebElements periodic table. https://www.webelements.com (1993) Accessed 27 Dec 2016

2. Eisenbud, M., Gesell, T.F.: Environmental Radioactivity from Natural, Industrial \& Military Sources: From Natural, Industrial and Military Sources. Academic Press, San Diego (1997)

3. Nirdosh, I., Muthuswami, S.: Distribution of ${ }^{230} \mathrm{Th}$ and other radionuclides in Canadian uranium mill streams. Hydrometallurgy 20, 31-47 (1988). doi:10.1016/0304-386X(88)90025-4

4. Tripathi, R., Sahoo, S., Jha, V., Khan, A., Puranik, V.: Assessment of environmental radioactivity at uranium mining, processing and tailings management facility at Jaduguda, India. Appl. Radiat. Isot. 66(11), 1666-1670 (2008). doi:10.1016/j.apradiso.2007.12.019

5. Paige, C., Kornicker, W., Hileman, O., Snodgrass, W.: Solution equilibria for uranium ore processing: the $\mathrm{BaSO}_{4}-\mathrm{H}_{2} \mathrm{SO}_{4}-\mathrm{H}_{2} \mathrm{O}$ system and the $\mathrm{RaSO}_{4}-\mathrm{H}_{2} \mathrm{SO}_{4}-\mathrm{H}_{2} \mathrm{O}$ system. Geochim. Cosmochim. Acta 62(1), 15-23 (1998). doi:10.1016/S0016-7037(97)00320-7

6. Carvalho, F., Madruga, M., Reis, M., Alves, J., Oliveira, J., Gouveia, J., Silva, L.: Radioactivity in the environment around past radium and uranium mining sites of Portugal. J. Environ. Radioact. 96(1), 39-46 (2007). doi:10.1016/j.jenvrad.2007.01.016

7. Zhang, T., Gregory, K., Hammack, R.W., Vidic, R.D.: Co-precipitation of radium with barium and strontium sulfate and its impact on the fate of radium during treatment of produced water from unconventional gas extraction. Environ. Sci. Technol. 48(8), 4596-4603 (2014). doi:10.1021/es405168b

8. Langmuir, D., Riese, A.C.: The thermodynamic properties of radium. Geochim. Cosmochim. Acta 49(7), 1593-1601 (1985). doi:10.1016/0016-7037(85)90264-9

9. Matyskin, A.V., Ebin, B., Tyumentsev, M., Allard, S., Skarnemark, G., Ramebäck, H., Ekberg, C.: Disassembly of old radium sources and conversion of radium sulfate into radium carbonate for subsequent dissolution in acid. J. Radioanal. Nucl. Chem. 310(2), 589-595 (2016). doi:10.1007/s10967016-4927-x

10. Brown, P.L., Ekberg, C., Ramebäck, H., Hedström, H., Matyskin, A.: Solubility of radium and strontium sulfate across the temperature range of 0 to $300^{\circ}$ C. In: Merkel, B.J., Arab, A. (eds.) Uranium-Past and Future Challenges, pp. 553-564. Springer, Berlin (2015) 
11. Monnin, C.: A thermodynamic model for the solubility of barite and celestite in electrolyte solutions and seawater to $200 \mathrm{C}$ and to 1 kbar. Chem. Geol. 153(1), 187-209 (1999). doi:10.1016/S00092541(98)00171-5

12. Kozempel, J., Vlk, M., Floriánová, M., Drtinová, B., Němec, M.: Dissolution of [ $\left.{ }^{226} \mathrm{Ra}\right] \mathrm{BaSO}_{4}$ as part of a method for recovery of 226Ra from aged radium sources. J. Radioanal. Nucl. Chem. 304(1), 337-342 (2015). doi:10.1007/s10967-014-3433-2

13. Nixon, A., Keller, D., Fritze, K., Pidruczny, A., Corsini, A.: Radium removal from Elliot Lake uraniummill solids by EDTA leaching. Hydrometallurgy 10(2), 173-186 (1983). doi:10.1016/0304386X(83)90004-X

14. Kuznetsov, R., Butkalyuk, P., Butkalyuk, I.: A rapid method for radium regeneration from its sulfate. Radiochemistry 55(1), 112-115 (2013). doi:10.1134/S1066362213010220

15. Shannon, R.T.: Revised effective ionic radii and systematic studies of interatomic distances in halides and chalcogenides. Acta Crystallogr. Sect. A Found. Crystallogr. 32(5), 751-767 (1976). doi:10.1107/ S0567739476001551

16. Rosenberg, Y., Metz, V., Oren, Y., Volkman, Y., Ganor, J.: Co-precipitation of radium in high ionic strength systems: 2. Kinetic and ionic strength effects. Geochim. Cosmochim. Acta 75(19), 5403-5422 (2011). doi:10.1016/j.gca.2011.07.013

17. Rosenberg, Y.O., Metz, V., Ganor, J.: Co-precipitation of radium in high ionic strength systems: 1. Thermodynamic properties of the $\mathrm{Na}-\mathrm{Ra}-\mathrm{Cl}-\mathrm{SO}_{4}-\mathrm{H}_{2} \mathrm{O}$ system-estimating Pitzer parameters for $\mathrm{RaCl}_{2}$. Geochim. Cosmochim. Acta 75(19), 5389-5402 (2011). doi:10.1016/j.gca.2011.06.042

18. Matyskin, A.V., Ylmen, R., Lagerkvist, P., Ramebäck, H., Ekberg, C.: Crystal structure of radium sulfate: an X-ray powder diffraction and density functional theory study. J. Solid State Chem. 253, 15-20 (2017). doi:10.1016/j.jssc.2017.05.024

19. Gran, G.: Determination of the equivalence point in potentiometric titrations. Part II. Analyst 77(920), 661-671 (1952)

20. Decay Data Evaluation Project, L.N.H.B., France. http://www.nucleide.org/DDEP_WG/DDEPdata.htm. Accessed 27 Dec 2016

21. Brønsted, J.N.: Studies on solubility. IV. The principle of the specific interaction of ions. J. Am. Chem. Soc. 44(5), 877-898 (1922). doi:10.1021/ja01426a001

22. Brønsted, J.N.: Calculation of the osmotic and activity functions in solutions of uni-univalent salts. J. Am. Chem. Soc. 44(5), 938-948 (1922). doi:10.1021/ja01426a003

23. Scatchard, G.: Concentrated solutions of strong electrolytes. Chem. Rev. 19(3), 309-327 (1936). doi:10. $1021 / \mathrm{cr} 60064 \mathrm{a} 008$

24. Guggenheim, E., Turgeon, J.: Specific interaction of ions. Trans. Faraday Soc. 51, 747-761 (1955)

25. Guillaumont, R., Fanghänel, T., Neck, V., Fuger, J., Palmer, D.A., Grenthe, I., Rand, M.H.: Update on the chemical thermodynamics of uranium, neptunium, plutonium, americium and technetium. Elsevier, Boston (2003)

26. Hummel, W., Anderegg, G., Rao, L., Puigdomenech, I., Tochiyama, O.: Chemical Thermodynamics of Compounds and Complexes of U, Np, Pu, Am, Tc, Se, Ni and Zr with Selected Organic Ligands, vol. 9. Elsevier, Boston (2005)

27. Brown, P.L., Ekberg, C.: Hydrolysis of Metal Ions. Wiley VCH, Weinheim (2016)

28. Felmy, A.R., Mason, M.J.: An aqueous thermodynamic model for the complexation of sodium and strontium with organic chelates valid to high ionic strength. I. Ethylenedinitrilotetraacetic acid (EDTA). J. Solution Chem. 32(4), 283-300 (2003). doi:10.1023/A:1023716703517

29. Botts, J., Chashin, A., Young, H.L.: Alkali metal binding by ethylenediaminetetraacetate, adenosine 5'triphosphate, and pyrophosphate*. Biochemistry 4(9), 1788-1796 (1965). doi:10.1021/bi00885a015

30. Daniele, P.G., Rigano, C., Sammartano, S.: Ionic strength dependence of formation constants. Alkali metal complexes of ethylenediaminetetraacetate nitrilotriacetate, diphosphate, and tripolyphosphate in aqueous solution. Anal. Chem. 57(14), 2956-2960 (1985). doi:10.1021/ac00291a046

31. Palaty, V.: Sodium chelates of ethylenediaminetetraacetic acid. Can. J. Chem. 41(1), 18-20 (1963). doi:10.1139/v63-004

32. Sal'nikov, Y., Boos, G., Gibadullina, K., Basyrova, R., Shakirova, N.: Ethylenediaminetetraacetate complexes of patassium and sodium and dissociation of EDTA in aqueous-acetonitrile and aqueousdioxane media. Russ. J. Inorg. Chem. 36(5), 745-749 (1991)

33. Daniele, P.G., Foti, C., Gianguzza, A., Prenesti, E., Sammartano, S.: Weak alkali and alkaline earth metal complexes of low molecular weight ligands in aqueous solution. Coord. Chem. Rev. 252(10), 1093-1107 (2008). doi:10.1016/j.ccr.2007.08.005

34. Marcus, Y., Hefter, G.: Ion pairing. Chem. Rev. 106(11), 4585-4621 (2006). doi:10.1021/cr040087x 
35. Allard, S., Ekberg, C.: Complexing properties of $\alpha$-isosaccharinate: stability constants, enthalpies and entropies of Th-complexation with uncertainty analysis. J. Solution Chem. 35(8), 1173-1186 (2006). doi:10.1007/s10953-006-9048-7

36. Schwarzenbach, G.V., Ackermann, H.: Komplexone V. Die Äthylendiamin-tetraessigsäure. Helv. Chim. Acta 30(6), 1798-1804 (1947). doi:10.1002/hlca.19470300649

37. Schwarzenbach, G., Gut, R., Anderegg, G.: Komplexone XXV. Die polarographische Untersuchung von Austauschgleichgewichten. Neue Daten der Bildungskonstanten von Metallkomplexen der Äthylendiamin-tetraessigsäure und der 1,2-Diaminocyclohexan-tetraessigsäure. Helv. Chim. Acta 37(4), 937-957 (1954). doi:10.1002/hlca.19540370402

38. Martell, A.E., Smith, R.M.: Critical Stability Constants, vol. 6. Springer, Berlin (1974)

39. Davies, C.W.: Ion Association. Butterworths, London (1962)

40. Stumm, W., Morgan, J.J.: Aquatic Chemistry: Chemical Equilibria and Rates in Natural Waters, vol. 126. John Wiley and Sons, New York (2012)

41. Carini, F.F., Martell, A.E.: Thermodynamic quantities associated with the interaction between ethylenediaminetetraacetate and alkaline earth ions. J. Am. Chem. Soc. 76(8), 2153-2157 (1954). doi:10.1021/ja01637a032

42. Schmid, R., Reilley, C.N.: A rapid electrochemical method for the determination of metal chelate stability constants. J. Am. Chem. Soc. 78(21), 5513-5518 (1956). doi:10.1021/ja01602a016

43. Astakhov, K., Fomenko, M.: The use of the Ca- 45 isotope in the determination of the instability constants of intracomplex compounds formed by alkali earth metals with ethylenediaminotetraacetic acid. Zh. Fiz. Khim. 31(9), 2110-2120 (1957)

44. Bohigian, T., Martell, A.: Progress Report US Atomic Energy Commission Contract No. AT,(30-1)$1823(1960)$

45. Jokl, V., Majer, J.: Investigation of complex compounds in solution using paper electrophoresis. IV. Complexes of 1,3-diamino-2-propanol-N, $N, \mathrm{~N}^{\prime}, \mathrm{N}^{\prime}$-tetraacetic acid. Chem. Vesti 19, 249-258 (1965)

46. Delgado, R., Da Silva, J.F.: Metal complexes of cyclic tetra-azatetra-acetic acids. Talanta 29(10), 815-822 (1982). doi:10.1016/0039-9140(82)80251-8

47. Nikolsky, B.P., Trofimov, A.M., Vysokoostrovskaya, N.B.: Complex formation of barium and radium in Trilon B solutions. Radiochemistry 1(2), 147-154 (1959)

48. Baetsle, L., Bengsch, E.: Ion-exchange characteristics of the radium-ethylene-diaminetetraacetate complex. J. Chromatogr. A 8, 265-273 (1962). doi:10.1016/S0021-9673(01)99257-X

49. Sekine, T., Kawashima, Y., Unnai, T., Sakairi, M.: Studies of the alkaline earth complexes in various solutions. IV. Solvent extraction study of radium(II) complexes with some aminocarboxylic acids in perchlorate media. Bull. Chem. Soc. Jpn. 41(12), 3013-3015 (1968). doi:10.1246/bcsj.41.3013

50. Nelson, F., Day, R., Kraus, K.: Anion exchange studies-XXX A number of elements in ethylenediaminetetraacetic acid solutions. J. Inorg. Nucl. Chem. 15(1-2), 140-150 (1960). doi:10.1016/00221902(60)80022-X

51. Anderegg, G.: Critical Survey of Stability Constants of EDTA Complexes: Critical Evaluation of Equilibrium Constants in Solution: Stability Constants of Metal Complexes. Elsevier, New York (2013)

52. Vdovenko, V.M., Dubasov, Y.V.: Analytical Chemistry of Radium. Wiley, New York (1976) 